\title{
Múltiplas identidades virtuais: a potencialização das experiências exploratórias do "eu"
}

\author{
José Carlos S. Ribeiro*
}

\begin{abstract}
Resumo
Este artigo propõe algumas reflexões acerca do processo de criação de múltiplas identidades virtuais comumente verificado em diversas plataformas interacionais on-line. Com este intuito, discute a caracterização, as possibilidades exploratórias (pessoais e sócio-comunicativas) e os motivos que levam os usuários a efetivarem tal prática. De forma adicional, busca identificar possiveis relações entre este procedimento e a promoção de uma dinâmica relacional diferenciada nestes ambientes de CMC (comunicação mediada por computador).
\end{abstract}

Palavras-chaves: Ciberespaço, interação social, identidade virtual

\begin{abstract}
This article proposes some reflections concerning the process of creation of multiple virtual identities usually verified in several platforms of on-line interaction. With this intention, it discusses characterizations, exploratory possibilities (personal and social-communicative) and reasons which lead users to execule such practice. In addirion to those, it seeks at identifying possible relations between this procedure and the promotion of a dynamics of clationships distinguished in these ambient of CMC (communication mediated by' computer).
\end{abstract}

Keywords: Cyerspace, social interaction, virtual identity'

\footnotetext{
- Doutor em Comunicação e Cuitura Contemporâneas (UFBa). Lider do Grupo de Pesquisa "Tecnologias Contemporâneas de Comunicação" . CNPq. Pesquisador participante do Centro Internacional de Estudos e Pesquisa em Cibercultura e do Grupo de Ciberpesquisa da FACOM/UFBa. Professor da Faculdade de Tecnologia e Ciências (FTC) e da Faculdade Dois de Julho (FDJ).
} 
Com os acentuados desenvolvimento e popularização das redes telemáticas, observa-se que os processos sócio-comunicativos e as estratégias comportamentais praticadas pelas pessoas que circulam nas diversas plataformas interacionais on-line tiveram o seu leque de ação ampliado. Uma dessas manifestações é a possibilidade de exploração de novos territórios existenciais, cognitivos e experienciais simultaneamente através do e pelo mundo virtual, que traz ao usuário a oportunidade de vivenciar diversas identidades a partir de um referencial distinto do comumente adotado no mundo off-line ${ }^{1}$. Embora pareça simples, este mecanismo de criação de identidades passa por uma série de etapas e adaptações que se fazem necessárias e condicionantes no processo transicional do mundo off-line para o on-line. Rituais de iniciação são utilizados a cada vez que os usuários transpõem esse percurso, haja vista a presença de marcadores cerimoniais de entrada (login), de nomeação, de competências, de sigilo (ARANHA, 1995, on-line).

Esses procedimentos de ingresso, longe de serem considerados como um conjunto de rotinas estritamente técnicas ou centradas apenas nos costumes e convenções, promovem a "imersão" das pessoas em uma ambiência social diferenciada, onde as referências comumente utilizadas no mundo off-line são colocadas em suspenso, ou mesmo redimensionadas quanto à sua importância e utilidade. Essas práticas, na verdade, credenciam seus usuários como portadores de passaportes virtuais, permitindo assim tanto o trânsito livre pelas diversas plataformas interacionais quanto a aparição do sentimento de pertença e o reconhecimento por parte dos demais integrantes como sujeitos constituintes e participantes de uma mesma ambiência social e de uma mesma experiência coletiva.

Tendo ultrapassado as "portas de entrada", através dos ritos iniciáticos, os usuários passam a ter à sua disposição, devido à natureza do meio e às práticas comumente adotadas (anonimato, uso de apelidos etc.), um leque bastante ampliado de possibilidades de combinações de características para a composição da "fachada pessoal" ou "identidade social" (GOFFMAN, 1975). De forma complementar, também têm aumentadas as possibilidades de estabelecer relações com diversas "identidades sociais" construídas pelos eventuais interlocutores.

Interessante notar que, segundo Goffman (1974), o processo de representação de papéis, através da criação de "fachadas pessoais" ou "identidades sociais", é executado na sociedade ocidental de tal forma que não interfere na constituição de uma singularidade do "eu", ou seja, independente das várias facetas requeridas e representáveis nas mais diversas situações contextuais, há uma básica assunção de que uma "identidade pessoal" com características biográficas é preservada. Seguindo essa linha argumentativa, parece que o comentário enquadra-se, de maneira aproximada, 
com as situações vivenciadas nas relações on-line, uma vez que a "identidade pessoal" estaria refletida e mantida na identidade vivenciada pelo usuário no mundo off-line, enquanto que as diversas "identidades sociais" estariam representadas pelas várias identidades virtuais criadas para transitar nos ambientes on-line.

Entretanto, conforme observa o autor, nas situações "face a face" (FTF) existe a possibilidade de que haja uma identificação mais profunda, em algumas circunstâncias e devido aos motivos mais diversos, entre a "identidade pessoal" e o papel desempenhado, o que poderia vir a promover alterações na estrutura de personalidade do indivíduo. De forma semelhante, tal fato também ocorreria no mundo on-line, onde alguns usuários poderiam vivenciar tão intensamente as identidades virtuais de modo que as respectivas características poderiam ser gradativamente incorporadas à sua maneira habitual de ser no mundo off-line. Em situações mais extremas, isso ocasionaria até mesmo uma percepção de equivalência entre as duas esferas relacionais (mundos on-line e off-line), conforme ilustra o depoimento de um usuário, citado por Turkle (1997, p. 18), sobre sua experiência nas diversas "janelas"? de sua vida:

Consigo desdobrar a minha mente. Estou a ficar perito nisso. Vejome a mim próprio como duas ou três ou mais pessoas. E limito-me a ligar uma parte de minha mente e depois outra, à medida que viajo de janela em janela. [...] A vida real é só mais uma janela e normalmente não é a que mais me agrada.

Como podemos perceber, há no discurso uma clara alusão a um processo de incremento do interesse pelas experiências derivadas das "janelas" online, ao lado de uma crescente desvalorização da importância dada à "janela" associada à vida real.

\section{A identidade no contemporâneo}

Como discutir essas novas configurações sociais, tendo em vista que o próprio conceito de identidade única, geralmente adotado para mapear os contatos on-line, mostra-se em processo de reavaliação de sua aplicabilidade na cultura contemporânea, conforme apontam alguns autores ao enfatizarem a 'estrutura plural do sujeito' (TURKLE, 1997)'? Weber (apud MAFFESOLI, 1987, p. 92), por exemplo, já prenunciava essa questão, ao afirmar que 'a identidade, do ponto de vista sociológico, é apenas um estado de coisas relativo e flutuante'. Mead (1934), através de seu famoso livro Mind, Self and Society from the Standpoint of a Social Behaviorist, já tinha proposto uma teoria de interação humana e de desenvolvimento da personalidade que 
apontava o caráter maleável, dinâmico e relacional presente na formação do processo identitário, destacando principalmente a sua composição tripartite (o "eu", o "mim" e o "outro generalizado") e a adoção de diversos papéis situacionais.

Maffesoli (1996), por sua vez, defende a idéia de que se vivencia na atualidade um momento de transição caracterizado pela mudança de uma lógica regida pelo princípio de identidade (vinculado à modernidade) para uma lógica de identificação (característico da pós-modernidade), onde se enfatiza mais a presença de um eu em construção, aberto - através de uma sucessão de identificações provisórias, intercambiáveis, proporcionadas e ajustadas às diversas demandas e variáveis presentes na vivência das situações contextuais - do que a visão de uma identidade única e autônoma, fechada, forjada em bases sólidas e estáveis. Para o autor, melhor seria adotar o conceito de pessoa do que o de indivíduo para caracterizar o momento presente, haja vista que aquele se insere em uma perspectiva mais relacional, mutável, enquanto este. se apresenta de uma forma mais permanente, não mais ajustada à realidade social contemporânea:

Relembro a distinção que pode ser feita entre indivíduo, que possui uma identidade precisa, faz sua própria história e participa, pelo contato com outros indivíduos, da história geral, e pessoa, que tem identificações múltiplas no âmbito de uma teatralidade global. $O$

174 indivíduo tem uma função racional, a pessoa desempenha papéis emocionais (MAFFESOLI, 1998, p. 107).

Analisando o processo de configuração identitária do sujeito e suas relações com as mudanças históricas ocorridas nos quadros de referências estruturais da sociedade, Hall (2002) aponta a presença de três concepções diferentes de identidade: (1) a primeira estaria vinculada ao "sujeito do iluminismo", sendo caracterizada basicamente pela idéia da existência de um indivíduo autônomo, integrado, centrado na razão e na unidade; (2) a segunda teria ligação com o chamado "sujeito sociológico", onde sua composição seria formatada a partir das relações interativas entre o "eu" e as instituições derivadas da sociedade moderna, que, embora complexa, possibilitaria a identificação com estruturas mais ou menós estáveis; (3) a terceira - do "sujeito pós-moderno" - apresentar-se-ia ancorada na percepção de um "eu" fragmentado, maleável e múltiplo, que se encontraria imerso em um mundo essencialmente mutável e dinâmico, onde as instituições mostrar-se-iam com uma configuração bastante instável. Hall (2002) destaca assim a gradativa transição ocorrida entre a concepção de uma identidade "centrada" - forjada no período iluminista - até aquela caracterizada pelo modelo "descentrado", mais perceptível e adequada aos dias atuais. 
Na construção histórica desse percurso, alguns autores salientam, com propriedade, o papel relevante das tecnologias comunicacionais. Meyrowitz (1985), por exemplo, explora a influência das mídias eletrônicas sobre os referenciais identitários e sua relação com as mudanças nos comportamentos sociais. Deste modo, as pessoas, não estando mais forçosamente limitadas às circunstâncias e às situações sociais localizadas em espaços geográficos próximos, teriam sua gama de experiências ampliada através do conhecimento e contato com outras realidades, valores e crenças. Thompson (1998), em uma perspectiva de análise semelhante, ressalta a crescente disponibilidade de formas e modelos simbólicos mediados, propiciada pelo desenvolvimento dos meios de comunicação, como um fator de natureza essencial na compreensão do mundo além dos locais de vida imediatos, e, consequientemente, na formação das referências situacionais necessárias (e estimulantes) para a expressão das diversas facetas identitárias.

Para os propósitos deste artigo, a discussão exaustiva sobre os termos mais adequados e precisos para retratar a presença do fenômeno das múltiplas identidades no cenário contemporâneo (não mais centradas em uma perspectiva uniforme e definitiva) é prescindível. O que nos interessa é, por um lado, a percepção da existência de um conjunto de quadros referenciais mutantes que viabiliza a emergência dessas manifestações e, por outro, o reconhecimento de que os avanços na área das tecnologias comunicacionais se tornaram parte fundamental na configuração desses quadros.

\section{A existência da identidade virtual e suas possibilidades exploratórias}

Diante do conjunto de peculiaridades verificadas nas situações contextuais promovidas pela maioria das plataformas interacionais, um intrigante aspecto faz-se notar: o fato da interatividade ser a fonte promotora da existência da identidade virtual. Embora tal situação seja observada de forma similar no mundo off-line, conforme postulam as teorias de cunho sóciointeracionistas, a originalidade resultante dela é derivada basicamente de dois aspectos: o primeiro é que este processo apresenta-se em um ambiente de natureza essencialmente permissiva, onde há uma grande possibilidade de exploração de novas facetas de personalidade e de práticas comportamentais; o segundo é que se efetiva em ambientes onde o fornecimento e a obtenção de informações sobre as identidades criadas e exercitadas no momento são efetuados em grande parte através do uso exclusivo da linguagem textual. Ou seja, é a interação, fomentada através de uma sucessão repetida de declarações e respostas trocadas entre os participantes na modalidade escrita, que permite às identidades criadas terem existência de fato. A rigor, podemos pensar que elas são construídas não apenas como elementos diretamente derivados das trocas comunicacionais 
travadas no ambiente, mas também de um complexo conjunto que contém, além do processo interacional efetivado com os demais participantes, as interações efetuadas com as máquinas (os computadores) e com os respectivos programas tecnológicos (os softwares).

Mesmo com a presença de uma maior flexibilidade e de um conjunto ampliado de possibilidades de experimentação, a identidade construída virtualmente também necessita de reconhecimento por parte dos outros para que exista de fato. Assim, o usuário precisa que haja uma complementaridade e uma cooperação, ou melhor, uma cumplicidade por parte dos interlocutores a fim de que possa se tornar, através da identidade criada e dos papéis representados, quem ele deseje ser naquele momento e naquele ambiente. $́$ É necessário que o outro entre no "jogo" pretendido pelo usuário para que seja possível o exercício das características e das práticas comportamentais escolhidas. No entanto, a questão torna-se mais complexa quando se reconhece que o outro não é um mero complemento passivo, mas sim um sujeito ativo que provavelmente também está exercitando e explorando novas possibilidades existenciais (de forma lúdica ou não).

Sem o aporte físico dos contatos tácteis, os usuários das plataformas interacionais on-line vivenciam um espaço de possibilidades, de quebra das "amarras" derivadas da presentificação do corpo real. Estando com um grande leque de opções de experimentação de outras formas de construção de seus contatos sociais em uma "cultura de simulação" (TURKLE, 1997), têm a 176 faculdade de poder criar de forma fragmentada vários sujeitos imaginários, potencializando a expressão "descentrada" de configuração identitária, tornando-se ainda mais distantes das referências que os sustentavam anteriormente, tais como a mesmice, o caráter contínuo e evolutivo da identidade única e a construção gradativa desta baseada na história pregressa do sujeito a partir de uma perspectiva linear.

Como resultado, há a criação de personagens que poderão corresponder ou não com partes da identidade constituída a partir do mundo off-line e que irão agir de acordo com as características selecionadas e se relacionar com outros seres virtuais que transitam no mesmo ambiente. Estando protegido pelo anonimato, o usuário pode projetar desejos e fantasias que venham a satisfazer suas carências e necessidades mais íntimas, mantendo contatos efêmeros ou até mesmo duradouros com outros personagens. Em outras palavras, nas plataformas interacionais o usuário passa a ser uma ou várias das identidades possíveis, transitando livremente dé acordo com as contingências e com seu próprio arbítrio, vivenciando novas e distintas situações através de uma sucessão rápida e cambiante de aspectos e características de si mesmo.

Há, desta forma, a possibilidade do usuário experienciar, de maneira lúdica, tanto um certo relaxamento da vigilância e da observação constante advinda do "poder disciplinador" (FOUCAULT, 1991) quanto um afastamento 
temporário, sendo este não de si, mas sim dos atributos e características representacionais habitualmente associados à identidade vivenciada no mundo off-line, permitindo, assim, explorar uma situação um tanto peculiar na qual ele é convertido em um objeto para si mesmo. Interessante perceber que esse conjunto de características aproxima-se da descrição de Augé (1994, p. 94) sobre a experiência possível (e prazerosa) do sujeito em um "não-lugar": "Objeto de uma suave possessão, à qual se abandona com mais ou menos talento ou convicção, como qualquer possuído, saboreia por um tempo as alegrias passivas da desidentificação e o prazer mais ativo da interpretação do papel". Existiria, desse modo, um certo prazer no fato de "soltar-se", mesmo que temporariamente, das "amarras" das referências identitárias construídas e sustentadas pelas experiências biológicas, históricas e sociais vividas no mundo off-line. Ou seja, há uma mudança de perspectiva: passa-se de uma percepção do tipo "eu sou o que os outros dizem que sou" para "eu sou o que quero ser".

O que Laing (1982) aponta, de forma prescritiva, como opção comportamental preventiva ao aparecimento de possíveis problemas psicológicos no indivíduo ${ }^{3}$, pode ser vivenciado, através do processo de "despersonalização controlada" e temporária verificado na construção e vivência de identidades on-line, como a pura expressão de experiências exploratórias de natureza lúdica e prazerosa.

Por outro lado, uma breve incursão pelos espaços místico-religiosos e pelos espaços literários nos mostra que tais perspectivas parecem retratar a questão da multiplicidade de identidades como um fenômeno que teria sua manifestação ocasionada a partir de algo que escaparia ao controle e à vontade do indivíduo. Seja por experiências científicas mal sucedidas ${ }^{4}$, por respostas a questões traumáticas profundamente enraizadas nos labirintos da personalidade ${ }^{5}$, por possessões de entidades divinas ${ }^{6}$ ou por determinantes puramente sociais, tais visões reforçam a idéia de que as várias possíveis facetas vivenciadas estariam sendo impostas "de fora para dentro", estando o indivíduo, em princípio, em situação de passividade. Uma circunstância na qual o indivíduo "cederia" ou "emprestaria", na maioria das vezes de maneira inconsciente e involuntária, sua constituição corpórea para ser habitada e utilizada temporariamente por outras identidades. De forma inversa a este ponto de vista, o usuário da rede coloca-se em uma posição extremamente ativa, uma vez que tais desdobramentos não são efetuados senão através da criação e inserção volitiva e consciente das várias identidades possíveis no ambiente on-line. Desta forma, não é seu corpo que é ocupado por outras identidades autônomas e sim ele que se apodera e utiliza-se de outros corpos (construídos virtualmente) para exercitar outras possibilidades comportamentais; e isso sendo efetuado de forma deliberada, consciente e controlada. 
Podemos pensar também que, na dinâmica verificada no am̉biente real, os desempenhos dos vários papéis estariam estabelecidos previamente e entrelaçados entre si, estando assim o sujeito "amarrado" e impèlido a segui-los e a representá-los de forma sequiencial (por exemplo, o papel de pai, de filho, de tio, de professor etc.), encaixando, na maioria das vezes; seus comportamentos nas circunstâncias socialmente determinadas e nas expectativas criadas por estes respectivos papéis. Os comentários de Goffman (1996, p. 34) reforçam essa linha de entendimento:

\begin{abstract}
Quando um ator assume um papel social estabelecido, geralmente verifica que uma determinada fachada já foi estabelecida para esse papel. Quer a investidura no papel tenha sido primordialmente motivada pelo desejo de desempenhar a mencionada tarefa, quer pelo desejo de manter a fachada correspondente, $o$ ator verificará que deve fazer ambas as coisas. Além disso, se um indivíduo assume um papel que não somente é novo para ele, mas também não está estabelecido na sociedade, ou se tenta modificar o conceito em que o papel é tido, provavelmente descobrirá a existência de várias fachadas bem estabelecidas entre as quais tem de escolher.
\end{abstract}

Entretanto, nas plataformas interacionais on-line não haveria, em princípio, papéis preestabelecidos a serem seguidos, uma vez que, de maneira contrária, seria o usuário quem determinaria e formataria os diversos papéis (vinculados às identidades escolhidas) e seus locais de inserção na teia social construída dentro dos espaços virtuais. Na realidade, é facultado ao usuário vivenciar as várias representações tanto em momentos diferenciados dentro do mesmo espaço (em uma mesma sala de bate-papo, por exémplo) "entrar" com um nickname em um determinado instante e na sequiência "entrar" com outro - quanto em espaços contextuais diversos de forma simultânea (estar em duas ou mais salas de bate-papo com identidades diferentes), através de um particular processo de narrativas sincrônicas de si mesmo. O que se apresenta é uma espécie de ampliação das possibilidades. de experienciar a multiplicidade dos "eus", seja pèla aceleração da circularidade dos papéis vivenciados, pela simultaneidade das "vivências paralelas", ou pela presença de um controle mais efetivo e mais consciente na representação dos mesmos. Nesse sentido, propomos uma dilatação do conceito de "identificações sucessivas"; apontado por Maffesoli (1996) pảra caracteriżar a situação (comum nos tempos contemporâneos) de frequiente permuta das faces do "eu", para a noção de "identificações paralelas", que nos afigura como mais adequada para retratar as práticas experienciais apontadas. 
Mas aqui uma pergunta se faz pertinente: por que os usuários se sentem impelidos a criar identidades múltiplas e alternativas que apresentam (ou não) características distanciadas daquelas presentes em sua vida cotidiana off-line? Como resposta mais ordinária podemos afirmar que tal fato se dá simplesmente porque eles podem fazê-lo, ou seja. porque existe um conjunto de fatores (técnicos e sociais) promovido e disponibilizado pelo ambiente comunicacional das diversas plataformas que, em certa medida. sugere essa prática. Ao mesmo tempo, podemos supor que a facilidade proporcionada pelo meio para a representação de papéis múltiplos, de acordo com a vontade ou desejo do usuário, teria. em princípio. a característica de possibilitar e promover o aprendizado de vários aspectos atrelados aos atributos da identidade escolhida, uma vez que a capacidade simbólica humana permite a aquisição de informações preditivas, sem passar pelos processos de aprendizagem por meio da experiência direta real. Nesse sentido, aqueles usuários que, por exemplo, tivessem comportamentos ou características tímidas e introvertidas poderiam explorar, de maneira instrutiva, personagens ou formas de atuação mais valorizadas socialmente.

Desse modo, as características escolhidas para compor a identidade virtual podem trazer elementos que ajudam o usuário a lidar com as situações difíceis do mundo off-line com as quais cosıuma defrontar-se. A criaçāo pode buscar uma "versão melhorada de si próprio" (TURKLE. 1997, p. 286). onde determinados atributos são ressaltados visando compensar ou complementar psicologicamente aspectos presentes em sua vida cotidiana, principalmente aqueles relacionados a uma percepção fragilizada da auto-imagem.

Através dessas identidades criadas e das relações advindas a partir delas, os usuários têm a oportunidade de vivenciar e lidar com os acontecimentos de uma forma menos traumática, adquirindo forças para enfrentá-los no dia-a-dia ${ }^{7}$, promovendo a possibilidade de um aumento da auto-estima. Isto pressupõe que a natureza expressiva do meio pode encorajar determinadas pessoas a desenvolver algumas habilidades sociais (por exemplo, exercitar o diálogo) e - em situações mais específicas - propiciar. inclusive, as primeiras experiências desses comportamentos em uma arena social.

A possibilidade de exploração de novos aspectos sociais e comportamentais, de "ver com outros olhos" certas situações. é outro dos motivos mais evidentes para se criar identidades virtuais e vivenciar experiências que dificilmente se teria acesso. A prática de experienciar fantasias das mais diversas ordens sem as barreiras e juízes sociais costumeiramente presentes na vida off-line, promove uma situação singular e ao mesmo tempo favorável ao aprendizado, proveniente do alargamento das lentes e do foco de análise sobre as várias situaçōes. Dessa forma, a facilidade de expressão de atos transgressivos pode representar: para alguns 
usuários, a possibilidade ímpar de vivenciar "os contrários" de seus hábitos comportamentais cotidianos; manifestados, por exemplo, através da passagem de uma estrutura "hipo", caracterizada pela escassez de determinadas práticas, para uma estrutura "hiper", marcada pelo excesso destas mesmas práticas (MAFFESOLI, 1985).

Entretanto, nem sempre os usuários estão buscando deliberadamente exercitar e desvendar aspectos reprimidos da personalidade ou aprender novas habilidades sociais ou "procedimentos" comportamentais necessários para o seu desenvolvimento e aprimoramento pessoal. Há aqueles casos em que a composição da identidade virtual se dá apenas visando a poșsibilidade de vivenciar os aspectos lúdicos da situação.

Em linhas gerais, o que se percebe é que as experiências derivadas da criação de identidades alternativas que transitam no mundo on=line proporcionam aos usuários uma ampliação do universo perceptivo e emocional associados ao mundo off-line, além da ocorrência de ocasionais inquietações existenciais e transformações pessoais.

Através das mais diversas óticas e perspectivas possibilitadas por essas experiências, o usuário tem a oportunidade de compreender um pouco da dinâmica psíquica e social que se apresenta na assunção de determinadas posturas ou condutas comportamentais, praticadas e vivenciadas a partir da adoção dos diversos papéis. Evidentemente, esse aspecto não é exclusivo das plataformas interacionais on-line, todavia pode ser expresso de uma 180 forma menos ameaçadora e mais controlável neste ambiente por parte do usuário que venha a vivenciá-lo.

Sob outro prisma de análise, uma suposição a ser considerada com relação às práticas adotadas é a de que as várias identidades criadas agiriam ou teriam comportamentos de acordo com as expectativas geradas a respeito delas. Assim, na identidade construída com características agressivas, por exemplo, haveria quase sempre uma expectativa (crença) de que seriam praticadas nas relações virtuais gestos ou comportamentos hostis, o que demonstraria, de certa forma, uma estabilidade de tendências comportamentais e, conseqüentēmente, umạ similaridade e regularidade na representação dos papéis criados, utilizando como referenciais comparativos aqueles vivenciados nas relações FTF. De outra maneira, podemos pensar que a prática habitual de criação de várias identidades (e suas respectivas representações) não se resumiria a uma simples apropriação de determinados estilos de conversação pontuais utilizando a rede, já que elas poderiam se mostrar sujeitas à aquisição de características e contornnos próprios, próximos ou não das referências identitárias FTF.

De acordo com uma perspectiva mais sistêmica, as identidades construídas estariam sempre em processo de reconfiguração em conformidade com os novos contextos e com as relações sociais (virtuais ou não) 
estabelecidas a cada momento. Tal posição estaria mais próxima daquela que Pearce (1996, p. 173) apresentou como sendo a metáfora do jogo, referindo-se às metáforas comunicacionais:

O jogo não é atgo que está fora, mas algo de que vocês são partes, e em cada momento suas ações respondem a um desenvolvimento e uma configuração de um desenho sempre mutante de acontecimentos. Suas ações vêm a ser parte deste processo de estruturação de um desenho que, na medida em que se configura, estabelece o contexto para os próximos eventos. Sem dúvida, não os fixa, já que é um processo que nunca se cristaliza porque os contextos vão se configurando permanentemente.

Ainda tendo como referência e guia para nossas reflexões a metáfora do jogo, podemos resgatar a categorização efetuada por Mead (1934) para demarcar dois momentos distintos e presentes no desenvolvimento da personalidade: o do "jogo livre" e o do "jogo regulamentado". O primeiro seria caracterizado como uma etapa onde a criança vivenciaria a livre expressão de papéis, onde a prática deste comportamento não seria (ainda) regida por um fim comum, compartilhado com as outras pessoas. O segundo teria como característica básica a presença de um alvo definido a ser alcançado, estando assim as relações estabelecidas e organizadas em função deste objetivo comum, o que, por sua vez, evidenciaria um estágio avançado de organização do "eu". Com certo cuidado, parece-nos ser possível utilizar tais asserções para se refletir sobre alguns aspectos presentes nas interações efetuadas nas diversas plataformas on-line. Em qual categoria de "jogo" poderíamos enquadrar o conjunto de ações efetivadas nestes ambientes? Será que poderíamos destacar aproximações ou afastamentos destas modalidades interacionais em relação ao primeiro e ao segundo modelo?

Tentando obter respostas a essas questões, podemos sugerir que os usuários experienciariam uma espécie de "retorno" a uma etapa anterior de desenvolvimento de sua personalidade', isto é, a um momento de exploração de possibilidades comportamentais (e existenciais) que não precisaria necessária e efetivamente estar atrelado à presença de uma harmonia representacional estabelecida e vivenciada pelos participantes do ambiente em torno de um fim ou objetivo comum. É evidente que isto não significa afirmar que a identidade virtual teria sua existência formada de maneira independente do processo relacional com os demais usuários. O que convém ser salientado é a presença de uma maior flexibilização no processo de adoção e representação dos papéis escolhidos e conseqüentemente no encaixe social resultante, haja vista não existir, de forma geral, um conjunto de ações predeterminadas que rejam tais contatos. Ou seja, não haveria um "jogo 
regulamentado", regido por uma lógica interna - previamente conhecida e acatada por todos - voltada para o alcance de un objetịo final.

\section{Considerações finais}

A partir das considerações expostas, podemos constatar que a ambiệncia on-line, de certa forman, potencializa as possibilidades de expressãa, ou melhor, de adoção, de desempenho e de controle de papéis por parte dos usuários nas "várias vidas" representadas pelas diversas "janelas" disponíveis. Tạl situaçãa, a rigor, nã̃o se revela desloçada dạ realidade do mundo off-line, uma vez que a possibilidade de vivenciar papéis virtuais múltiplos mostra-se inserida na prática da multiplicidade de papéis presentes em diversos aspectos da vida cotidiana. No entanto, a questão apresentạda é que a estrutura plural do sujeito terịa suạ manifétestação caracterizạda (e acentuada) nạa apenas pela representaçạao de vários papéis efetivados de forma sequiencial, alternada - de acơơơ e em resposta aos variados cenários e mọmentos vividos, através de um contínuo movimento de caracterização e descaracterização de atributos, verifiçados nos contatos FTF - mas também pela possibilidade de vivenciạr distintos papéis (com suas respectivas caracterizações) de forma simultâneạ, descentralizada e nạ̃o hiẹrarquizada.

\section{Notas}

! Embora controverso sob o ponto de vista conceitual, devido à facilidade de sua associação com uma presumida visão tecnicista da realidade, o emprego dos termos "on-line" e "off-line" " para çaracterizar e diferenciar, respectivamente, as "vivệncias" situadas no ambiente vịtual e aquelas vividas no ambiente tridimensional do mundo físico - é mantido neste artigo, tendo em vista a sua ampla utilizaçăo, tanto no meio exclusivamente técnico, quanto nas discussões efetivadas dentro da esferạ acadêmica,

2 "Janela" - área ou estação de trabalho visualmente disnonível para o usuário que possibilita a interface com os diversos programas de computador.

${ }^{3}$ Segundo Laing (1982, p. 51-52), "a pessoa deveria conhecer os riscos de um rompimento com a realidade sociạl, isto é, fazer tentativas deliberadas e sistemáticas para não ser o self que todo mundo o considera, fụgir à própria identidade, simular não estar presente, ser anônimo ou incógnitọ, adotatar pseudônimimos, dizer que está morto, que não é ninguém porque o próprio corpo não lhe pertence". 
"Como exemplo, ver a fiç̧ão literária "O Médico e o Monstro", de R. L. Stevenson, Ed. Nova Fronteira, Rio de Janeiro, 1992.

5

A redação contida no Manual Diagnóstico e Estatística de Transtornos Mentais (4 ${ }^{a}$ edição DSM-IV), referente ao tópico 300.14 Transtorno Dissociativo de Identidade (antigo transtorno de personalidade múltipla) é bastant

e ilustrativa a este respeito:

'[...] Cada estado de personalidade pode ser vivenciado como se possuísse uma história pessoal distinta. auto-imagem e identidade própria, inclusive um nome diferente. Em geral existe uma identidade primária, portadora do nome correto do indivíduo, a qual é passiva, dependente, culpada e depressiva. As identidades alternativas com frequiência têm nomes e características diferentes que contrastam com a identidade primária (p.ex. são hostis, controladoras e auto-destrutivas). Identidades particulares podem emer

gir em circunstâncias específicas, diferindo em termos de idade e gênero declarado, vocabulário e conhecimentos ou afeto predominante ,

"Nesse aspecto, podemos citar o fenômeno da "baixa" de orixás e de outras divindades nas práticas ritualísticas presentes em algumas religiōes de origem africana (candomblé, umbanda), assim como a incorporação de seres desencarnados verificada em "sessões espíritas", cultuadas pelos adeptos da religião espírita-kardecista.

${ }^{7}$ Sobre este ponto, Turkle (1997) apresenta uma série de exemplos interessantes (ver principalmente as páginas 278, 279, 300. 301, 304 e 310 ).

${ }^{8}$ Tal suposição assemelha-se àquela observada por Holland (1996) sobre a possível "regressão" vivenciada pelos usuários.

\section{Referências Bibliográficas}

ARANHA FILHO, Jayme. Tribos eletrônicas: usos e costumes. On-line: 1995. Disponivel em www.alternex.com.br esocius/t-jayme.html (26/03/2005).

AUGÉ, Marc. Não-lugares: introdução a uma antropologia da supermodernidade. Campinas: Papirus, 1994.

FOUCAULT, Michel. Vigiar e punir: história da violência nas prisões.

Petrópolis: Vozes, 1991.

GOFFMAN, Erving. A representação do eu na vida cotidiana. Petrópolis: Vozes, 1996.

. Estigma: notas sobre a manipulação da identidade deteriorada.

Rio de Janeiro: Zahar, 1975. 
Frame analysis: an essay on the organization of experience.

New York: Harper \& Row, 1974.

HALL, Stuart. A identidade cultural na pós-modernidade. Rio de Janeiro:

DP\&A, 2002.

HOLLAND, Norman. The Internet Regression, On-line: 1996. Disponível em www.rider.edu/users/suler/psycyber/holland.html (26/03/2005)

LAING, Ronald. D. O eu e os outros. $O$ relacionamento interpessoal.

Petrópolị: Vozes, 1982.

MAFFESOLI, Michel, A sombra de dionísio: contribuição para uma sociologia da orgia. Rio de Janeiro: Graal, 1985.

O tempo das tribos: o declinio do individualismo nas sociedades

de massa. Rio de Janeiro: Forense, 1987. . No fundo das aparências. Petrópolis: Vozes, 1996. O O elogio da razão sensível. Petrópolis: Vozes, 1998.

MEAD, George. Mind self and society from the standpoint of a social behaviorist. On-line: 1934. Disponível em http://spartan.ac.brocku.ca/ rlward/Mead/pubs2/mindself/Mead_1934_toc.html (26/03/2005).

MEYROWITZ, Joshua. No sense of place: the impact of electronic media on social behavior, Oxford: Oxford University Press, 1985.

PEARCE, W. Barnett: Novos modelos e metáforas comunicacionais: a passsagem da teoriąa à prática, do ọbjetivismo ao construcionismo social e da representação à reflexidade. In: SCHINITMAN, Dora. Novos

184 paradigmas, cultura e subjetividade. Porto Alegre: Artes Médicas, 1996. THOMPSON, John. A mídia e a modernidade: uma teoria social da mídia. Petrópolis: Vozes, 1998.

TURKLE, Sherry. A vida no ecrã: a identidade na era da internet. Lisboạ:Rel.D'ágụa, 1997. 